\title{
Ncf1 affects osteoclast formation but is not critical for postmenopausal bone loss
}

\author{
Alexandra Stubelius ${ }^{1 *}$, Annica Andersson ${ }^{1}$, Rikard Holmdahl ${ }^{3}$, Claes Ohlsson ${ }^{2}$, Ulrika Islander ${ }^{1}$ and Hans Carlsten ${ }^{1}$
}

\begin{abstract}
Background: Increased reactive oxygen species and estrogen deficiency contribute to the pathophysiology of postmenopausal osteoporosis. Reactive oxygen species contribute to bone degradation and is necessary for RANKLinduced osteoclast differentiation. In postmenopausal bone loss, reactive oxygen species can also activate immune cells to further enhance bone resorption. Here, we investigated the role of reactive oxygen species in ovariectomyinduced osteoporosis in mice deficient in Ncf1, a subunit for the NADPH oxidase 2 and a well-known regulator of the immune system.

Methods: B10.Q wild-type (WT) mice and mice with a spontaneous point mutation in the Ncf1-gene (Ncf1*/*) were ovariectomized (ovx) or sham-operated. After 4 weeks, osteoclasts were generated ex vivo, and bone mineral density was measured using peripheral quantitative computed tomography. Lymphocyte populations, macrophages, pre-osteoclasts and intracellular reactive oxygen species were analyzed by flow cytometry.

Results: After ovx, $\mathrm{Ncf}_{1 *}^{*}{ }^{*}$-mice formed fewer osteoclasts ex vivo compared to WT mice. However, trabecular bone mineral density decreased similarly in both genotypes after ovx. NCf1***-mice had a larger population of preosteoclasts, whereas lymphocytes were activated to the same extent in both genotypes.

Conclusion: $\mathrm{Ncf}^{*} /{ }^{*}$-mice develop fewer osteoclasts after ovx than WT mice. However, irrespective of genotype, bone mineral density decreases after ovx, indicating that a compensatory mechanism retains bone degradation after ovx.

Keywords: Reactive Oxygen Species, Neutrophil cytosolic factor 1, Ncf1, Postmenopausal bone loss, NOX 2, Estrogen Deficiency, Bone mineral density, Osteoclasts, Osteoimmunology, Pre-osteoclasts
\end{abstract}

\section{Background}

Bone remodeling occurs throughout life, shifting to favor bone resorption in postmenopausal women. Osteoclasts (OCL) resorb bone, and the presence of reactive oxygen species (ROS) at the interface between OCL and bone suggests a role for ROS in bone resorption [1-4]. ROS are produced by membrane-localized nicotinamide adenine dinucleotide phosphate (NADPH) oxidases (NOX); [5], where NOX 1, 2, and 4 are active in OCL and their myeloid precursor cells $[1,4]$. The activity of NOX 2 is regulated by the neutrophil cytosolic factor 1 (Ncf1, alias p47 ${ }^{\text {phox }}$ ) subunit [6]. ROS from NOX 2 kills bacteria in professional phagocytes (such as macrophages and

\footnotetext{
* Correspondence: alexandra.stubelius@rheuma.gu.se

'Department of Rheumatology and Inflammation Research, Centre for Bone and Arthritis Research (CBAR), Sahlgrenska Academy, University of Gothenburg, Box 48040530 Göteborg, Sweden

Full list of author information is available at the end of the article
}

neutrophils with highly efficient phagocytosis), and damages cells and tissues during inflammation. However, reduced production of ROS in mice lacking Ncf1 promotes T-cell dependent autoimmune diseases [6]. Further, Tcells activated by antigen presenting cells (APCs) induce bone degradation in postmenopausal osteoporosis. After ovariectomy (ovx), the excess tumor necrosis factor alpha (TNF $\alpha$ ) from T-cells activates OCL and results in reduced bone density [7-9]. Other mechanisms underlying postmenopausal bone loss include increased receptor activator of nuclear factor $\kappa \mathrm{B}$ ligand (RANKL) signaling [10] and increased OCL formation [11].

To investigate the role of ROS and Ncf1 in postmenopausal bone loss, we employed a postmenopausal boneloss model by ovx or sham operating mice with a spontaneous mutation in Ncf1. We investigated osteoclastogenesis ex vivo, used peripheral quantitative computed 
tomography (pQCT) for measuring bone mineral density (BMD), and flow cytometry was used to investigate preOCL and immune cells, including immune cell activation. We found that bone mineral density decreased to the same extent in both Ncf1-deficient mice and wild type (WT) mice, however, the OCL formation and preosteoclast populations were differentially affected in the two genotypes.

\section{Methods}

\section{Animal procedures}

The regional ethical review board in Gothenburg approved this study. The point mutation in Ncf1 [12] has been backcrossed onto the B10Q background (WT) [6] and kept in breeding. WT mice and mice derived from the same background but with a homozygous mutation in the Ncf1-gene $\left(\mathrm{Ncfl}^{*} / *\right)$ were housed in a temperature-controlled room with a 06.00-18.00 h light cycle and consumed a soy-free diet (R70, Lantmännen, Stockholm, Sweden) and tap water ad libitum.

\section{Ovariectomy and treatment}

At 7 to 10 weeks of age, female mice were ovariectomized or sham-operated, under isoflurane (Baxter Medical Ab, Kista, Sweden) anesthetization by inhalation. Carprofen (Orion Pharma AB, Animal Health, Sollentuna, Sweden) was administered subcutaneously as postoperative analgesic.

Mice were implanted with slow release pellets containing placebo or $17 \beta$-Estradiol (E2) at the time of ovx (0.05 mg E2 $/ \mathrm{kg} /$ day; 90-day release, Innovative Research of America, Sarasota, FL). The animals were randomly divided into 3 groups per genotype (6-9 mice per group): sham + placebo, ovx + placebo or ovx + E2. Treatment continued until study termination (4 weeks).

\section{Tissue collection}

Mice were terminated 4 weeks after ovx or sham operations. At the time of termination, mice were anesthetized with ketamine (Pfizer AB, Täby, Sweden) and medetomidine (Orion Pharma AB), bled and killed by cervical dislocation. Mice body weights were recorded (WT sham $25 \pm 3.2$ g, WT Ovx $25 \pm 3.0$ g, Ncf1*/* Sham $25 \pm 1.7$ g, Ncf1*/* Ovx $25 \pm 1.5 \mathrm{~g}$ ), uteri were weighed and one femur was put in $4 \%$ paraformaldehyde (PFA) for measuring BMD. One femur and two tibiae (for osteoclast differentiation) and one humerus (for FACS analysis) were put in phosphate buffered saline (PBS).

\section{Osteoclast differentiation}

Bone-marrow derived macrophages (BMM) were cultured and stimulated with macrophage colony stimulating factor (M-CSF) and RANKL to induce osteoclast differentiation [13]. Bone marrow was flushed with minimum essential medium Eagle's alpha modification ( $\alpha M E M ;$ Gibco, Grand Island, NY, USA) supplemented with $10 \%$ heat-inactivated fetal bovine serum (FBS; Sigma-Aldrich ${ }^{\oplus}$, St Louis, USA). Cells were incubated for 2 days at $37{ }^{\circ} \mathrm{C}$ in a humidified $\mathrm{CO}_{2}$ chamber on a culture dish (Corning, Hickory, NC, USA) with $\alpha$ MEMmedium containing $30 \mathrm{ng} / \mathrm{ml}$ M-CSF (R\&D system Europe LTD, Abingdon, UK). After two days, the adhering cells (BMMs) were detached, after which 5000 cells in $5 \mu \mathrm{l} \alpha \mathrm{MEM} / 10 \%$ FBS were seeded at the center of 96well plates and left to adhere for $10 \mathrm{~min}$. Subsequently, $200 \mu \mathrm{l}$ medium was added containing either $30 \mathrm{ng} / \mathrm{ml}$ of M-CSF (controls), or $30 \mathrm{ng} / \mathrm{ml} \mathrm{M-CSF}+2 \mathrm{ng} / \mathrm{ml}$ of RANKL. After 4 days, the cells were fixed and stained for tartrate-resistant acid phosphatase (TRAP). TRAPpositive cells with $\geq 3$ nuclei were considered osteoclasts. The amounts of TRAP-positive multinucleated osteoclasts were calculated by standardized counting of the midsection of a 96-well by Osteomeasure 3.2.1.0 software (Osteometrics, Inc., Decatur, GA, USA) [14]. The total OCL covered area in the well was calculated by tracing the OCL boundaries. Area per individual OCL was calculated by dividing OCL covered area with number of OCL. Three mice per group were used and assayed in quadruplicate.

\section{Assessing BMD}

After being kept for 2 days in $4 \%$ PFA and subsequently stored in $70 \%$ ethanol, femurs were scanned using peripheral quantitative computed tomography (pQCT) with Stratec $\mathrm{pQCT}$ XCT Research M software (version 5.4B; Norland, Fort Atkinson, WI, USA), at a resolution of $70 \mu \mathrm{m}$, as described previously [15]. Cortical thickness was determined by one mid-diaphyseal scan at a distance from the distal growth plate corresponding to $36 \%$ of total femur length. This mid-diaphyseal region of mouse femur only contains cortical bone. Trabecular BMD was determined by one metaphyseal scan at a distance from the distal growth plate corresponding to $3 \%$ of the femur length. The trabecular bone region was set as $45 \%$ of the inner total cross-sectional area.

\section{Single cell preparation and immunophenotyping by flow cytometry}

Single cell suspensions for flow cytometry were prepared from bone marrow as previously described [16]. Erythrocytes were lysed using Tris-buffered $0.83 \% \mathrm{NH}_{4} \mathrm{Cl}$. Cells were then stained with fluorochrome-conjugated antibodies to detect different cell populations (Table 1). Fluorescence-minus-one stained samples were used as controls. Data was acquired on a BD FACS Canto II and analyzed using Flow Jo 8.8.6 (Three Star Inc, Ashland, USA). Macrophages were defined as $\mathrm{CD}_{11 \mathrm{~b}^{+}}{\mathrm{M}-\mathrm{CSFR}^{+}}^{+}$ cells; and pre-osteoclasts defined as $\mathrm{CD}_{11 \mathrm{~b}^{+} \mathrm{M}-\mathrm{CSFR}}$ 
Table 1 Antibody table

\begin{tabular}{|c|c|c|c|c|}
\hline $\begin{array}{l}\text { Peptide/protein } \\
\text { target }\end{array}$ & Name of Antibody & $\begin{array}{l}\text { Manufacturer, catalog \#, and/or name of individual } \\
\text { providing the antibody }\end{array}$ & $\begin{array}{l}\text { Species raised in; monoclonal } \\
\text { or polyclonal }\end{array}$ & $\begin{array}{l}\text { Dilution } \\
\text { used }\end{array}$ \\
\hline M-CSFR & $\begin{array}{l}\text { APC anti-mouse CD115 } \\
\text { (CSF-1R) }\end{array}$ & Biolegend, \#135510 & Rat, monoclonal & $1: 10$ \\
\hline CD11b & V450 anti-mouse CD11b & BD Biosciences, \#560455 & Rat, monoclonal & $1: 50$ \\
\hline CD8 & PE anti-mouse CD8 & BD Biosciences, \#553033 & Rat, monoclonal & $1: 50$ \\
\hline CD8 & PerCp anti-mouse CD8 & BD Biosciences, \#553036 & Rat, monoclonal & $1: 50$ \\
\hline CD4 & V450 anti-mouse CD4 & BD Biosciences, \#560468 & Rat, monoclonal & $1: 50$ \\
\hline CD69 & PE anti-mouse CD69 & BD Biosciences, \#561932 & $\begin{array}{l}\text { Armenian Hamster, } \\
\text { monoclonal }\end{array}$ & $1: 30$ \\
\hline CD11c & APC anti-mouse CD11c & BD Biosciences, \#550261 & $\begin{array}{l}\text { Armenian Hamster, } \\
\text { monoclonal }\end{array}$ & $1: 50$ \\
\hline MHC ॥ & $\begin{array}{l}\text { PerCp anti-mouse I - A/I-E } \\
(\text { MHC II) }\end{array}$ & Biolegend, \#107624 & Rat, monoclonal & $1: 50$ \\
\hline CD80 & $\begin{array}{l}\text { Pacific Blue anti-mouse } \\
\text { CD80 }\end{array}$ & Biolegend, \#104724 & Armenian Hamster, polyclonal & $1: 10$ \\
\hline RANK & $\begin{array}{l}\text { PE anti-mouse CD265 } \\
\text { (RANK) }\end{array}$ & Biolegend, \#119806 & Rat, monoclonal & $1: 20$ \\
\hline
\end{tabular}

${ }^{+} \mathrm{RANK}^{+}$cells. Median Fluorescence Intensity, MFI, was calculated of RANK expression on $\mathrm{CD}_{11 \mathrm{~b}^{+} \mathrm{M}-}$ CSFR $^{+}$cells.

\section{Estimation of ROS production}

Dihydrorhodamine (DHR) 123 dye was used as a free radical sensor (final concentration of $0.25 \mu \mathrm{g} / \mathrm{ml}$, Life Technologies, Carlsbad, CA, USA), which forms the fluorescent product rhodamine 123 after oxidation. To quantify the respiratory burst activity, bone marrow cells were incubated at $37{ }^{\circ} \mathrm{C}$ for $15 \mathrm{~min}$ with phorbol myristate acetate (PMA, $0.5 \mu \mathrm{g} / \mathrm{ml}$; SigmaAldrich). Cells were washed with cold PBS, acquired by a BD FACS Canto II (BD Biosciences, San Jose, CA, USA), and analyzed using Flow Jo software (FlowJo, LLC, Ashland, OR, USA).

\section{Statistical analysis}

Statistical evaluations were performed using IBM SPSS Statistics for Macintosh, Version 22.0.0.0, released 2013 (IBM Corp, Armonk, NY, USA). As bone mineral density measurements are sensitive to sibling controls, statistical analysis was only used to compare mice of the same genotypes. Student's $t$ test was used for comparison of two groups. Whenever Levene's test revealed unequal variances between the groups, Welch's $t$-test was used instead. Logarithmic transformations were used when appropriate to ensure normal distribution of data. $P$ values $<0.05$ were considered statistically significant. GraphPad Prism version 6.0c was used for graphical representations. Reported values are mean \pm SD unless otherwise stated.

\section{Results \\ Osteoclastogenesis increases after ovx in WT mice but not in $\mathrm{Ncf} 1 * / *$-mice}

Osteoclastogenesis was induced from bone marrow cells. We found an increase in the number of OCL formed ex vivo after ovx in WT mice (Fig. 1a). However, in the $\mathrm{Ncf1}^{*} / *$-mice, the number of OCL formed did not increase after ovx (Fig. 1a). The total OCL area did not differ between the groups (Fig. 1b). We confirmed the reduced estrogen levels after ovx in both genotypes by measuring uteri weights (WT sham $77 \pm 41 \mathrm{mg}$, WT ovx $12 \pm 1.6 \mathrm{mg}$, $p<0.0001$; Ncf1*/*- Sham $95 \pm 30 \mathrm{mg}, \mathrm{Ncfl}^{*} / *$ - ovx $13 \pm$ $4.1 \mathrm{mg}, p<0.0001)$. We further confirmed that monocyte/ macrophages from WT mice produced more ROS than $\mathrm{Ncfl}^{* / *}$-mice (Geometric mean fluorescence intensity (gMFI): WT sham $542 \pm 70, \mathrm{Ncfl}^{*} / *$ Sham $283 \pm 89$ ).

\section{Ncf1 does not regulate ovx-induced bone loss}

We measured BMD 4 weeks after ovx in both WT and $\mathrm{Ncf1}^{* / *}$-mice. pQCT measurements revealed equally reduced trabecular BMD after ovx in WT and Ncf1*/ *-mice (Fig. 2a). Cortical thickness had decreased significantly in the WT mice after ovx, but only borderline in the $\mathrm{Ncf1}^{*} / *$-mice (Fig. 2b). To investigate a possible ratedependency of bone degradation after ovx, we also analyzed BMD 2 weeks after ovx in both genotypes. Trabecular BMD had decreased significantly in both genotypes, whereas cortical thickness had not decreased in either genotype at this earlier time point (data not shown). We further investigated whether both genotypes responded to E2 treatment after ovx-induced bone degradation. We found that after 4 weeks of treatment, trabecular BMD (WT-E2 $692 \pm 73 \mathrm{mg} / \mathrm{cm}^{3}$, Ncf1*/*-E2 625 $\pm 116 \mathrm{mg} / \mathrm{cm}^{3}$ ) and cortical thickness (WT-E2 $0.23 \pm$ 

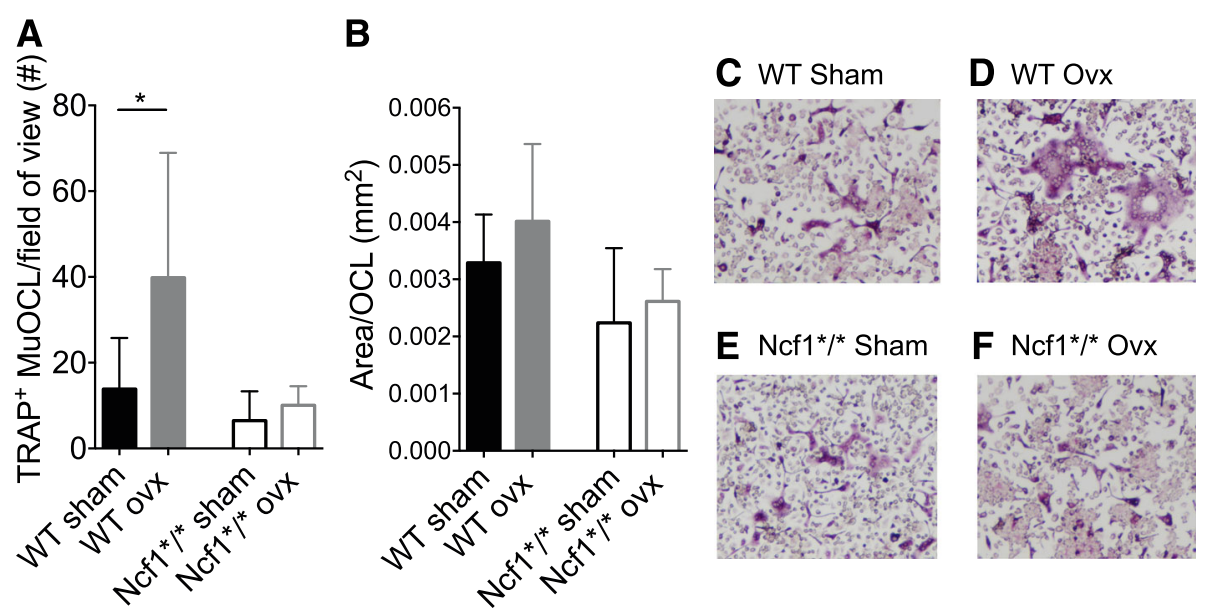

Fig. 1 Ovx of WT mice induces osteoclast formation, but not ovx of $\mathrm{Ncfl}^{* / *}$-mice. Number $\mathbf{a}$ and area $\mathbf{b}$ of OCL formed ex vivo in wild-type (WT) and Ncf1-deficient $\left(\mathrm{Ncfl}^{* / *}\right)$ mice after ovx or sham operations. In C-F, representative images of OCL are shown from the respective groups. Three mice per group were used and assayed in quadruplicate. Data displays mean $\pm S D,{ }^{*} p<0.05$ in sham versus ovx mice

$0.01 \mathrm{~mm}, \mathrm{Ncf1} / *$-E2 $0.23 \pm 0.03 \mathrm{~mm}$ ) increased in both WT and Ncf1*/*-mice with this dose of E2. We also confirmed uteri growth after E2 treatment in both WT and Ncf1*/*-mice (WT-E2 $208 \pm 46 \mathrm{mg}, \mathrm{Ncf1}^{*} / *$ - E2 $185 \pm$ $60 \mathrm{mg})$.

\section{RANK-expressing pre-OCL increase after ovx in Ncf1*/ *-mice}

The two factors M-CSF and RANKL are important in the formation of OCL [17]. The cytokine M-CSF influences hematopoietic stem cells in the bone marrow to differentiate into the family of macrophages. OCLs forms from this M-CSF-dependent precursor, shared with macrophages. When OCL precursors are incubated with RANKL, these cells can further differentiate through the RANK receptor and fuse into multinucleated OCL. To evaluate the importance of Ncf1 in the formation of macrophages and pre-osteoclasts, we analyzed cells from the bone marrow using flow cytometry. The frequency of macrophages expressing the M-CSF receptor

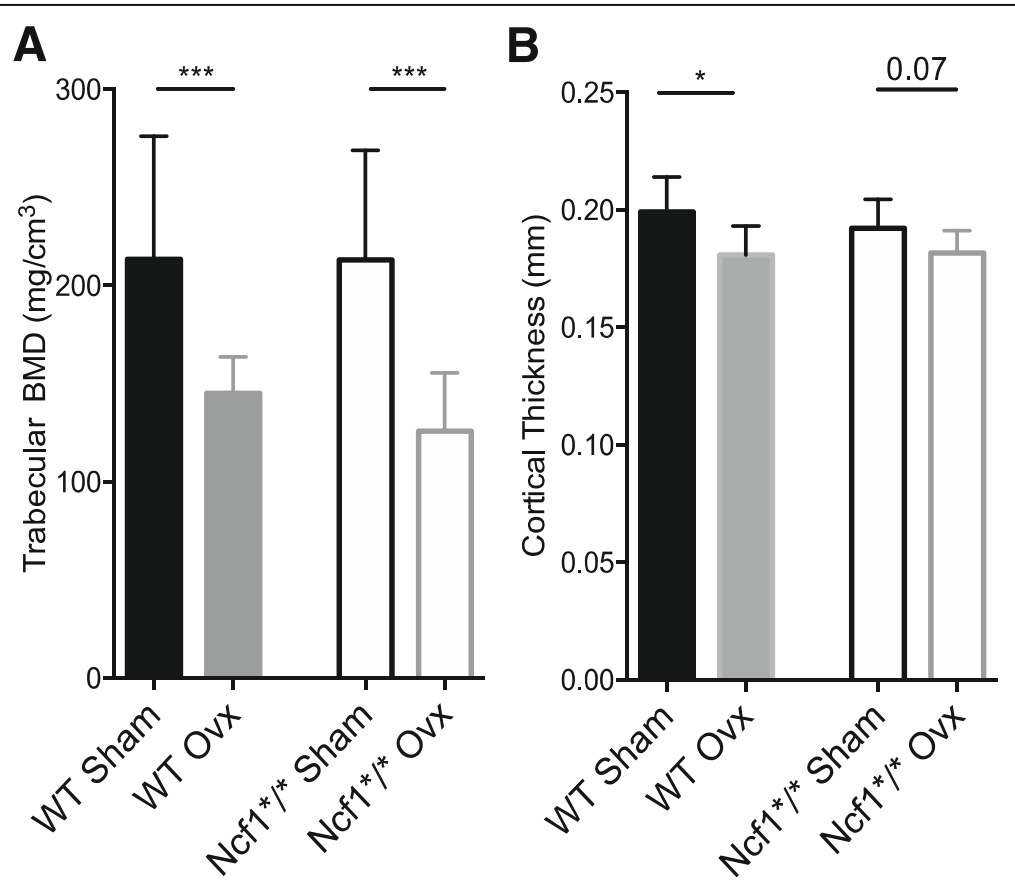

Fig. 2 BMD decreases in both WT and $\mathrm{Ncf1}^{* / *}$-mice after ovx. Mice were either ovx- or sham-operated for 4 weeks. Trabecular bone mineral density and cortical thickness were evaluated by $\mathrm{pQCT} \mathbf{a}-\mathbf{b}$. Data displays mean $\pm \mathrm{SD},{ }^{*} p<0.05,{ }^{* * *} p<0.001$ in sham versus ovx mice 
did not differ in either genotype (Fig. 3a). Neither did the frequency of cells expressing F4/80 (results not shown). However, the population of pre-osteoclastic macrophages expressing RANK expanded in Ncf1*/*-mice after ovx, but not in WT mice (Fig. 3b). There was no difference in MFI expression of RANK (Fig. 3d).

\section{Ovx leads to lymphocyte activation in both genotypes}

According to previous studies, lymphocytes are involved in the activation of OCL after ovx [7]. Ovx triggers APCs to activate T-cells in order to stimulate OCL activity. Neither the general dendritic cell (DC) population $\left(\mathrm{CD} 11 \mathrm{c}^{+}\right.$cells) nor the MHC class $\mathrm{II}^{+} \mathrm{DCs}$ were affected in either genotype 2 or 4 weeks after ovx (Table 2). The $\mathrm{CD} 80^{+} \mathrm{DCs}$ expanded in the $\mathrm{Ncf} 1^{*} / *$-mice 4 weeks after ovx (Table 2). The general $\mathrm{CD}^{+}{ }^{+} \mathrm{T}$-cell population decreased after ovx (Table 2), whereas the $\mathrm{CD} 69^{+} \mathrm{CD} 4^{+}$ cells increased in both genotypes 2 weeks after ovx (Table 2). Similar results were found for the $\mathrm{CD} 69^{+} \mathrm{CD} 8^{+}$ cell population (Table 2).

\section{Discussion}

Bone resorption and bone formation shifts with advancing age, leading to loss of bone mass and strength. In postmenopausal women, both age and loss of estrogens contribute to activating osteoclasts, inflammatory cells, and induce ROS production in the bone marrow. In our study, we found that ovx increases OCL formation ex vivo in WT mice, accompanied by reduced cortical thickness and trabecular BMD. In Ncf1*/* mice, no increase in OCL formation was seen after ovx, indicating that the $\mathrm{Ncfl}^{*} / *$ should retain bone density after ovx. Surprisingly, the Ncf1*/* mice loose BMD similar to WT mice after ovx.

We investigated several possible mechanisms for this found discrepancy. First, we investigated whether the difference was present already on pre-OCL in the bone marrow (defined as $\mathrm{CD}_{11 \mathrm{~b}^{+} \mathrm{M}-\mathrm{CSFR}^{+} \mathrm{RANK}^{+} \text {macro- }}$ phages) destined to become OCL upon stimulation. The crucial role of Ncf1 for macrophage activation was previously shown where Ncf1 deleted specifically in macrophages regulated chronic inflammation [18-20]. In our study, Ncf1** mice showed an expanded population of pre-osteoclastic macrophages expressing RANK after ovx (Fig. 3b), indicating that they are target cells also in this model. One compensatory mechanism could be to increase OCL sensitivity and upregulate RANK. We could however not find any differences in the intensity of RANK expression using FACS (Fig. 3d). In addition, $\mathrm{Ncfl}^{*} / *$ did not affect OCL area. This suggests that the OCL retain their efficiency regardless of numbers, and implies that it is the total bone area covered by the OCL that is important. Previous studies have implicated that NOX 1, 2 and 4 are important in bone loss. The OCL has been shown to switch NOX-complex in order to produce the necessary levels of ROS, possibly as a compensatory mechanism to ensure an adequate bone resorption process [21]. NOX 4 was shown to be more active in bone resorption in young mice [22], whereas the NOX 2 complex was shown to be important for bone loss in elderly mice (more than 2 years of age [23]. Those studies verified the importance of the two NOX complexes for bone resorption at different ages, and suggest that NOX 4 may compensate for lost ROS production in $\mathrm{Ncfl}^{*} / *$ mice.

The bone remodeling process was comparably regulated by estrogen treatment in this study, as treating ovx mice with E2 resulted in similar increases in cortical thickness and trabecular BMD in both Ncf1*** and WTmice. However, interactions between E2 and Ncf1 were possibly concealed in this study due to the high dose and duration of the estrogen treatment.

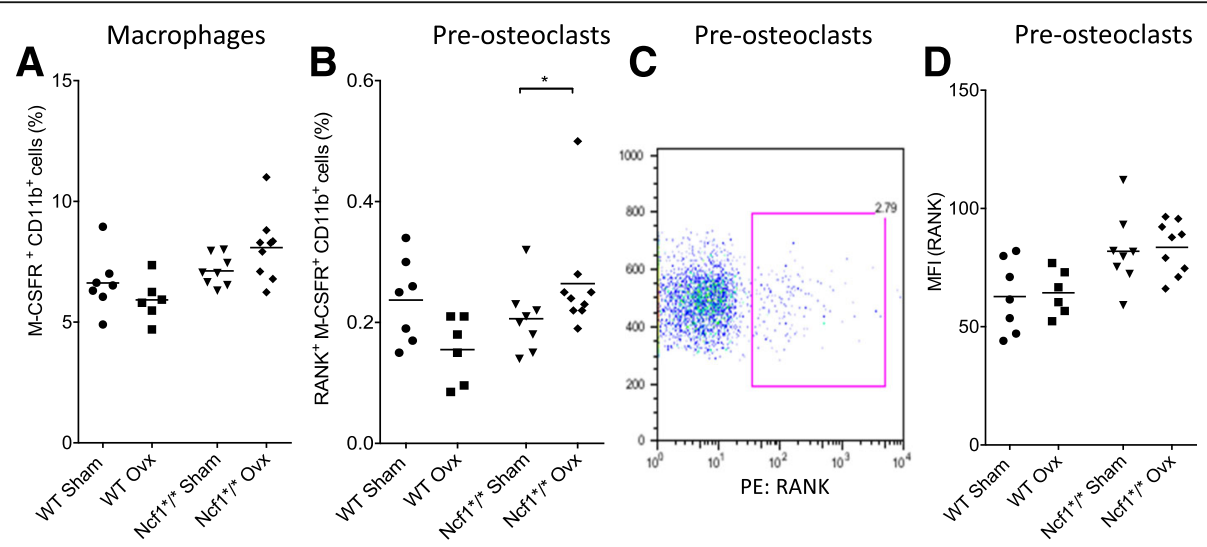

Fig. 3 Pre-osteoclasts expand in $\mathrm{NCF}^{* / *}$-mice after ovx. Bone marrow cells were evaluated using FACS. Populations of macrophages $\left(\%\right.$ CD $11 \mathrm{~b}^{+}$

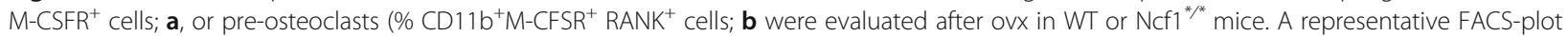
of RANK expression on CD11 $\mathrm{b}^{+} \mathrm{M}$-CSFR ${ }^{+}$cells is displayed in $\mathbf{c}$, and Median Fluorescent Intensity, MFI expression for RANK on CD11 $\mathrm{b}^{+} \mathrm{M}-\mathrm{CFSR}^{+}$ cells is presented in $\mathbf{d}$. Data displays mean $\pm \mathrm{SD},{ }^{*} p<0.05$ in sham versus ovx mice 
Table 2 Lymphocyte frequencies (mean \%) after ovx in WT and Ncf1-deficient mice ( $n=6-9$ mice per group, $t$-test comparing ovx vs. sham for each genotype)

\begin{tabular}{|c|c|c|c|c|c|c|c|}
\hline Leukocyte population & Sub population & WT Sham $(\%, \pm S D)$ & WT ovx $(\%, \pm S D)$ & $p$-value & Ncf1*** Sham $(\%, \pm S D)$ & $\mathrm{Ncf1}^{*} /{ }^{*}$ ovx $(\%, \pm \mathrm{SD})$ & $p$-value \\
\hline \multicolumn{8}{|l|}{4 weeks after ovx } \\
\hline \multirow[t]{3}{*}{ DCs $\left(C D 11 c^{+}\right)$} & & $2.5 \pm 0.9$ & $2.4 \pm 0.2$ & n.s. & $2.3 \pm 0.7$ & $2.6 \pm 0.5$ & n.s. \\
\hline & $\mathrm{MHC} \mathrm{I}^{+}$ & $44 \pm 10$ & $44 \pm 9.2$ & n.s. & $49 \pm 16$ & $51 \pm 16$ & n.s. \\
\hline & $\mathrm{CD} 80^{+}$ & $19 \pm 3.8$ & $17 \pm 4.3$ & n.s & $18 \pm 4.1$ & $25 \pm 8.4$ & 0.04 \\
\hline \multirow[t]{2}{*}{ T-cell $\left(\mathrm{CD}^{+}{ }^{+}\right)$} & & $1.6 \pm 0.3$ & $0.8 \pm 0.2$ & $<0.0001$ & $1.2 \pm 0.3$ & $0.93 \pm 0.3$ & 0.04 \\
\hline & $\mathrm{CD}_{6} 9^{+}$ & $22 \pm 6$ & $26 \pm 5.5$ & n.s & $24 \pm 8.8$ & $33 \pm 8.0$ & n.s \\
\hline \multirow[t]{2}{*}{ T cell $\left(\mathrm{CD}^{+}\right)$} & & $1.4 \pm 0.2$ & $0.74 \pm 0.2$ & $<0.0001$ & $0.94 \pm 0.4$ & $0.8 \pm 0.3$ & n.s \\
\hline & $\mathrm{CD}_{6} 9^{+}$ & $17 \pm 7.4$ & $23 \pm 3.7$ & n.s & $21 \pm 7.7$ & $25 \pm 8.0$ & n.s \\
\hline \multicolumn{8}{|l|}{2 weeks after ovx } \\
\hline \multirow[t]{3}{*}{$\mathrm{DCs}\left(\mathrm{CD} 11 \mathrm{c}^{+}\right)$} & & $7.3 \pm 0.9$ & $6.6 \pm 0.1$ & n.s. & $6.6 \pm 1.0$ & $6.2 \pm 1.1$ & n.s. \\
\hline & $\mathrm{MHC} \mathrm{I}^{+}$ & $40 \pm 6.0$ & $38 \pm 2.9$ & n.s. & $37 \pm 4.8$ & $36 \pm 4.4$ & n.s. \\
\hline & $\mathrm{CD} 80^{+}$ & $30 \pm 3.0$ & $24 \pm 3.2$ & 0.001 & $31 \pm 4.2$ & $25 \pm 4.6$ & 0.03 \\
\hline \multirow[t]{2}{*}{ T-cell $\left(\mathrm{CD}^{+}{ }^{+}\right)$} & & $2.1 \pm 0.5$ & $0.7 \pm 0.2$ & $<0.0001$ & $2.3 \pm 0.6$ & $1.1 \pm 0.5$ & 0.001 \\
\hline & $\mathrm{CD}_{6} 9^{+}$ & $21 \pm 5.3$ & $33 \pm 8.4$ & 0.002 & $19 \pm 6.5$ & $26 \pm 3.2$ & 0.02 \\
\hline \multirow[t]{2}{*}{ T cell $\left(\mathrm{CD}^{+}\right)$} & & $2.2 \pm 0.9$ & $0.8 \pm 0.2$ & $<0.001$ & $2.0 \pm 1.3$ & $0.56 \pm 0.16$ & 0.01 \\
\hline & $\mathrm{CD} 9^{+}$ & $9.8 \pm 2.3$ & $19 \pm 5.0$ & $<0.001$ & $12 \pm 3.7$ & $25 \pm 8.5$ & 0.002 \\
\hline
\end{tabular}

In previous studies of postmenopausal bone loss, activated T cells and APCs were shown to regulate the bone resorption process [7]. Since Ncf1 regulates auto-reactive T cells through APCs in autoimmunity, we further investigated activated T cells and DCs. We found similar changes at 2 weeks in both $\mathrm{WT}$ and $\mathrm{Ncfl}^{*} / *$ mice, whereas at 4 weeks after ovx, the $\mathrm{CD} 80^{+} \mathrm{DCs}$ population was expanded in the $\mathrm{Ncfl}^{*} / *$-mice. This indicates a possible rate difference, and that a target mechanism lies further up in the hierarchy, such as on the pre-OCL or macropages, or on soluble factors secreted from the activated APCs. TNF $\alpha$ is produced in abundance after ovx, and can induce osteoclastogenesis by itself. A possible discrepancy between OCL formation after stimulation with RANKL, TNF $\alpha$ and other cytokines in the $\mathrm{Ncfl}^{*} /{ }^{*}$-mice will be subject for further studies. Both the increased RANK- expression on macrophages and lingering increased $\mathrm{CD}^{-} 0^{+} \mathrm{DCs}$ in $\mathrm{Ncf}^{*} / *$-mice could contribute to an altered bone degradation process, such as we discerned of the cortical bone in $\mathrm{Ncf} 1^{*} / *$-mice. The lack of statistically significant difference in cortical thickness of $\mathrm{Ncfl}^{*} / *$-mice could either be due to a too small number of animals used in each group, or it is possible that other more sensitive BMD measurement techniques such as microCT could detect finer details and differences in the rate dependent bone degradation processes, thus revealing additional aspects regarding effects of $\mathrm{Ncfl}$ on bone. The model we used in this study is a global Ncf1-deficiency model, reducing Ncf1 function in all cells. Therefore, possible mechanisms regulated by Ncf1 includes effects on osteoblasts, altered regulation of the cross-talk between osteoblasts and OCL, compensatory ROS production from another NOX or regulating another mechanism altogether, all of which are subjects for future studies.

\section{Conclusion}

Here, using a model of postmenopausal bone loss, we report that Ncf1, an essential subunit of the ROSproducing NOX 2 complex, contributes to OCL formation possibly by regulating pre-OCL. The NOX complexes are active in many physiological and pathophysiological processes. Increasing our understanding of their function will help in producing new targets for alleviating disease.

\section{Abbreviations}

APC: Antigen presenting cell; BMD: Bone mineral density; BMM: Bonemarrow derived macrophages; DC: Dendritic cell; E2: 17ß-Estradiol; FBS: Fetal bovine serum; gMFl: Geometric mean fluorescence intensity; M-

CSF: Macrophage colony stimulating factor; MFI: Median fluorescence intensity; NADPH: Nicotinamide adenine dinucleotide phosphate; Ncf1: Neutrophil cytosolic factor 1; NOX: NADPH oxidase; OCL: Osteoclast; OVX: Ovariectomy; PBS: Phosphate buffered saline; PFA: Paraformaldehyde; PMA: Phorbol myristate acetate; pQCT: peripheral quantitative computed tomography; RANKL: Receptor activator of nuclear factor k B ligand; ROS: Reactive oxygen species; TNFa: Tumor necrosis factor alpha;

TRAP: Tartrate-resistant acid phosphatase; WT: Wild type; aMEM: Minimum essential medium Eagle's alpha modification

\section{Acknowledgements}

We thank Anette Hansevi PhD, Malin Erlandsson, PhD for excellent technical assistance and Margareta Rosenqvist and Christina Björklund for animal care.

\section{Funding}

These studies were funded in part by the COMBINE network, the Swedish Research Council 2011-2521, ALF-medel Västra Götalandsregionen (ALFGBG145331) and Reumatikerfonden, R-83041, R-230371. The FACS Canto II was bought thanks to generous support from the Inga-Britt and Arne Lundberg Foundation. 


\section{Availability of data and materials}

The datasets supporting the conclusions of this article are available from the corresponding author on reasonable request.

\section{Authors' contributions}

The six authors are justifiably credited with authorship, according to the authorship criteria. In detail: Study design. AS, UI, HC. Acquisition of data. AS, $A A, U I, C O$. Analysis and interpretation of data. AS, AA, RH, CO, UI, HC. Statistical analysis. AS. Writing of manuscript. AS, UI, HC. All authors have given their final approval of the manuscript.

\section{Competing interests}

The authors declare that they have no competing interests.

\section{Consent for publication}

Not applicable.

\section{Ethics approval and consent to participate}

This study was carried out in strict accordance with the recommendations by the regional ethical review board in Gothenburg (permit numbers 592009 and 30-2010). All surgery was performed under isoflurane inhalation anesthesia, Carprofen was administered subcutaneously as a postoperative analgesic, and all efforts were made to minimize suffering.

\section{Author details}

'Department of Rheumatology and Inflammation Research, Centre for Bone and Arthritis Research (CBAR), Sahlgrenska Academy, University of Gothenburg, Box 48040530 Göteborg, Sweden. ${ }^{2}$ Department of Internal Medicine and Clinical nutrition, Centre for Bone and Arthritis Research (CBAR), Sahlgrenska Academy, University of Gothenburg, Gothenburg, Sweden. ${ }^{3}$ Medical Inflammation Research, Karolinska Institutet, Stockholm, Sweden

Received: 1 June 2016 Accepted: 28 October 2016

Published online: 09 November 2016

\section{References}

1. Lee NK, Choi YG, Baik JY, Han SY, Jeong DW, Bae YS, Kim N, Lee SY. A crucial role for reactive oxygen species in RANKL-induced osteoclast differentiation. Blood. 2005;106(3):852-9.

2. Key Jr LL, Ries WL, Taylor RG, Hays BD, Pitzer BL. Oxygen derived free radicals in osteoclasts: the specificity and location of the nitroblue tetrazolium reaction. Bone. 1990;11(2):115-9.

3. Key Jr LL, Wolf WC, Gundberg CM, Ries WL. Superoxide and bone resorption. Bone. 1994;15(4):431-6.

4. Steinbeck MJ, Appel Jr WH, Verhoeven AJ, Karnovsky MJ. NADPH-oxidase expression and in situ production of superoxide by osteoclasts actively resorbing bone. J Cell Biol. 1994;126(3):765-72.

5. Leto TL, Morand S, Hurt D, Ueyama T. Targeting and regulation of reactive oxygen species generation by Nox family NADPH oxidases. Antioxid Redox Signal. 2009;11(10):2607-19.

6. Hultqvist M, Olofsson P, Holmberg J, Backstrom BT, Tordsson J, Holmdahl R. Enhanced autoimmunity, arthritis, and encephalomyelitis in mice with a reduced oxidative burst due to a mutation in the $\mathrm{Ncf1}$ gene. Proc Natl Acad Sci U S A. 2004;101(34):12646-51.

7. Grassi F, Tell G, Robbie-Ryan M, Gao Y, Terauchi M, Yang X, Romanello M, Jones DP, Weitzmann MN, Pacifici R. Oxidative stress causes bone loss in estrogen-deficient mice through enhanced bone marrow dendritic cell activation. Proc Natl Acad Sci U S A. 2007;104(38):15087-92.

8. Adeel S, Singh K, Vydareny KH, Kumari M, Shah E, Weitzmann MN, Tangpricha $V$. Bone loss in surgically ovariectomized premenopausal women is associated with T lymphocyte activation and thymic hypertrophy. J Investig Med. 2013;61(8):1178-83.

9. Hultqvist M, Backlund J, Bauer K, Gelderman KA, Holmdahl R. Lack of reactive oxygen species breaks $T$ cell tolerance to collagen type II and allows development of arthritis in mice. J Immunol. 2007;179(3):1431-7.

10. Srivastava S, Toraldo G, Weitzmann MN, Cenci S, Ross FP, Pacifici R. Estrogen decreases osteoclast formation by down-regulating receptor activator of NF-kappa B ligand (RANKL)-induced JNK activation. J Biol Chem. 2001; 276(12):8836-40
11. Shevde NK, Bendixen AC, Dienger KM, Pike JW. Estrogens suppress RANK ligand-induced osteoclast differentiation via a stromal cell independent mechanism involving c-Jun repression. Proc Natl Acad Sci U S A. 2000; 97(14):7829-34.

12. Huang CK, Zhan L, Hannigan MO, Ai Y, Leto TL. P47(phox)-deficient NADPH oxidase defect in neutrophils of diabetic mouse strains, C57BL/6 J-m db/db and db/+. J Leukoc Biol. 2000;67(2):210-5.

13. Takeshita S, Kaji K, Kudo A. Identification and characterization of the new osteoclast progenitor with macrophage phenotypes being able to differentiate into mature osteoclasts. J Bone Miner Res. 2000;15(8):1477-88.

14. Stralberg F, Henning P, Gjertsson I, Kindlund B, Souza PP, Persson E, Abrahamson M, Kasprzykowski F, Grubb A, Lerner UH. Cysteine proteinase inhibitors regulate human and mouse osteoclastogenesis by interfering with RANK signaling. FASEB J. 2013;27(7):2687-701.

15. Windahl SH, Vidal O, Andersson G, Gustafsson JA, Ohlsson C. Increased cortical bone mineral content but unchanged trabecular bone mineral density in female ERbeta(-/-) mice. J Clin Invest. 1999;104(7):895-901.

16. Stubelius A, Wilhelmson AS, Gogos JA, Tivesten A, Islander U, Carlsten H. Sexual dimorphisms in the immune system of catechol-O-methyltransferase knockout mice. Immunobiology. 2012;217(8):751-60.

17. Souza PP, Lerner UH. The role of cytokines in inflammatory bone loss. Immunol Invest. 2013:42(7):555-622.

18. Gelderman KA, Hultqvist M, Pizzolla A, Zhao M, Nandakumar KS, Mattsson R, Holmdahl R. Macrophages suppress T cell responses and arthritis development in mice by producing reactive oxygen species. J Clin Invest. 2007;117(10):3020-8.

19. Pizzolla A, Gelderman KA, Hultqvist M, Vestberg M, Gustafsson K, Mattsson R, Holmdahl R. CD68-expressing cells can prime T cells and initiate autoimmune arthritis in the absence of reactive oxygen species. Eur $J$ Immunol. 2011;41(2):403-12.

20. Pizzolla A, Hultqvist M, Nilson B, Grimm MJ, Eneljung T, Jonsson IM, Verdrengh M, Kelkka T, Gjertsson I, Segal BH, et al. Reactive oxygen species produced by the NADPH oxidase 2 complex in monocytes protect mice from bacterial infections. J Immunol. 2012;188(10):5003-11.

21. Sasaki H, Yamamoto H, Tominaga K, Masuda K, Kawai T, Teshima-Kondo S, Matsuno K, Yabe-Nishimura C, Rokutan K. Receptor activator of nuclear factor-kappaB ligand-induced mouse osteoclast differentiation is associated with switching between NADPH oxidase homologues. Free Radic Biol Med. 2009;47(2):189-99.

22. Goettsch C, Babelova A, Trummer O, Erben RG, Rauner M, Rammelt S, Weissmann N, Weinberger $V$, Benkhoff $S$, Kampschulte M, et al. NADPH oxidase 4 limits bone mass by promoting osteoclastogenesis. J Clin Invest. 2013;123(11):4731-8.

23. Chen JR, Lazarenko OP, Blackburn ML, Mercer KE, Badger TM, Ronis MJ. p47phox-Nox2-dependent ROS Signaling Inhibits Early Bone Development in Mice but Protects against Skeletal Aging. J Biol Chem. 2015;290(23): 14692-704.

\section{Submit your next manuscript to BioMed Central and we will help you at every step:}

- We accept pre-submission inquiries

- Our selector tool helps you to find the most relevant journal

- We provide round the clock customer support

- Convenient online submission

- Thorough peer review

- Inclusion in PubMed and all major indexing services

- Maximum visibility for your research

Submit your manuscript at www.biomedcentral.com/submit
C Biomed Central 